\title{
Releases from transparent blue automobile coatings containing nanoscale copper phthalocyanine and their effects on J774 A1 macrophages
}

\author{
Chengfang Pang ${ }^{\mathrm{a}}$, Nicole Neubauer ${ }^{\mathrm{b}}$, Matthew Boyles ${ }^{\mathrm{c}}$, David Brown ${ }^{\mathrm{c}}$, Nilesh Kanase ${ }^{\mathrm{c}}$, \\ Danail Hristozov $^{\mathrm{a}}$, Teresa Fernandes ${ }^{\mathrm{c}}$, Vicki Stone ${ }^{\mathrm{c}}$, Wendel Wohlleben ${ }^{\mathrm{b}}$, Antonio Marcomini ${ }^{\mathrm{a}, *}$ \\ a Department of Environmental Sciences, Informatics and Statistics, University Ca' Foscari Venice, 30172 Mestre, VE, Italy \\ b BASF SE, Material Physics, Ludwigshafen, Germany \\ ${ }^{\text {c } H e r i o t-W a t t ~ U n i v e r s i t y, ~ S c h o o l ~ o f ~ L i f e ~ S c i e n c e s, ~ N a n o s a f e t y ~ R e s e a r c h ~ G r o u p, ~ U K ~}$
}

\section{A R T I C L E I N F O}

\section{Keywords:}

Occupational health

Copper Phthalocyanine

nanoparticles

sanding

cytotoxicity

\begin{abstract}
A B S T R A C T
Nanoscale copper phthalocyanine (n-CuPc) is a pigment widely used in paints to enhance automobile coatings and to make colors transparent and more appealing to users. Despite the benefits, n-CuPc can potentially be released into the environment and pose risks in occupational settings. Assessing the toxicity of released n-CuPccontaining fragments is thus important for the acceptance of $\mathrm{n}$-CuPc products. This paper presents the first combined study addressing both the release of n-CuPc-containing fragments from commercial coatings in realistic occupational situations and the hazard of the released fragments using a macrophage model.

Sanding was used to produce fragments from automobile coatings with n-CuPc as well as from a reference coating with the same matrix composition but without n-CuPc. Size distribution and agglomeration of these fragments in Rosewell Park Memorial Institute (RPMI) cell culture medium was studied before conducting a battery of cytotoxicity experiments. Cell viability and reactive oxygen species (ROS) production were conducted and particle localization within cells was analyzed.

The results show similar size and number distribution of fragments when comparing the reference and $\mathrm{n}-\mathrm{CuPc}$ fragments. The n-CuPc fragments showed higher agglomeration in RPMI than pristine n-CuPc. We found that toxicity of the $\mathrm{n}-\mathrm{CuPc}$ fragments and reference materials was similar $\left(\mathrm{EC}_{50}\right.$ Frag n-CuPc $=242.9 \mu \mathrm{g} \mathrm{ml}^{-1} ; \mathrm{EC}_{50}$ Frag Refer $\left.=241.6 \mu \mathrm{g} \mathrm{ml}^{-1}\right)$ and below the toxicity of pristine $\mathrm{n}-\mathrm{CuPc}\left(\mathrm{EC}_{50} \mathrm{n}-\mathrm{CuPc}=151.1 \mu \mathrm{g} \mathrm{ml}{ }^{-1}\right)$. The results demonstrated that embedding $\mathrm{n}-\mathrm{CuPc}$ in matrix used in automobile coatings reduced the toxicity and release when $\mathrm{n}$-CuPc is used in paints. Our finding can be used to support design of n-CuPc-enabled products used in automobile applications.
\end{abstract}

\section{Introduction}

Phthalocyanine blue is based on the phthalocyanine chromophore, which is synthesized from phthalonitrile or from phthalic anhydride and urea. It was first synthesized in the 1930's, and is still a very popular pigment since it offers high performance at a relatively low cost (less than \$20 per kilogram) (Chemical Economics Handbook, 2011; Kittel, 1974). Its large, symmetrical structure, containing conjugated double-bonds, makes it a stable, intensely colored compound that is the basis for what has become the leading group of colorants in several applications.
Nanoscale copper phthalocyanine (n-CuPc) has been utilized to enhance or modify the properties of many materials and products, including printing inks, coatings for automobile production, plastics and textiles (Chemical Economics Handbook, 2011; Hans Kittel, 1974). nCuPc can improve the mechanical properties and add new features to the products, such as improved transparency, lightfastness (stability under irradiation), heat stability, chemical and bleed resistance, improved processing capabilities and durability. It is estimated that Europe consumed 21 thousand metric tons of CuPc pigments (dry weight basis, both as nano-forms (n-CuPc) and as non-nano-forms) in 2010 , of which $25-30 \%$ were used in paints and coatings, a significant

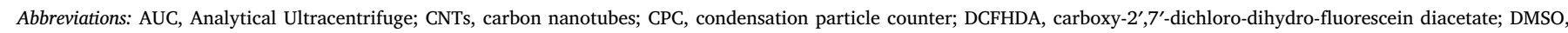

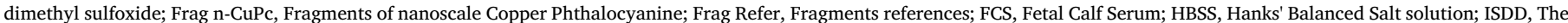

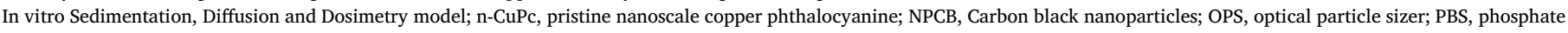
buffered saline; RPMI, Rosewell Park Memorial Institute; ROS, reactive oxygen species; SEM, Scanning Electron Microscopy

* Corresponding author at: Department of Environmental Sciences, Informatics and Statistics, Ca' Foscari University of Venice, Via Torino 155, 30172 Mestre, VE, Italy.

E-mail address: marcom@unive.it (A. Marcomini). 
part in nanoform (Chemical Economics Handbook, 2011). The automobile industry is the largest market for organic pigments due to the increasing customer preferences for enhanced colors.

The use of n-CuPc can potentially lead to a release of n-CuPc which may pose environmental and occupational risks, especially to automechanics performing car maintenance and repairs. Even though the automobile industry has risk management measures in place (local exhaust of sanding equipment, face masks) to reduce occupational exposure, the knowledge on fate and hazard of sanding fragments is required for efficient risk management. Only one study addressed release of n-CuPc from coatings (Göhler et al., 2013), and very little is known about the exposure and hazard of released n-CuPc from automobile coatings in environmental and occupational settings.

This is the first study addressing the cytotoxicity of released n-CuPc fragment in macrophages. Macrophages, as a part of the cell-mediated immune system, exhibit phagocytic activity, during which the cell can phagocytose pathogens or particles, forming vesicles resulting in either biodegradation (Zhang et al., 2015; Zhao et al., 2011), antigen presentation or physical clearance via cell migration. These cells may therefore be exposed to potentially relatively high doses of particles. Macrophages can produce reactive oxygen species (ROS) and free radical species in response to foreign materials. These ROS are normally neutralized by antioxidants in the body, but this process becomes ineffective during prolonged or excessive inflammation or during disease when antioxidants become depleted leading to oxidative stress. Oxidative stress at low levels can activate defense mechanisms such as the up-regulation of antioxidant defenses, but at higher (non-lethal) levels oxidative stress can stimulate the production of pro-inflammatory mediators leading to inflammation which can exacerbate or cause disease. Even higher levels of oxidative stress are associated with genotoxicity and cell death (Lin and Beal, 2006; Lobo et al., 2010; Paiva and Bozza, 2014; Bhattacharyya et al., 2014).

We measured the release of $\mathrm{n}$-CuPc-containing fragments from automobile coatings through a sanding approach, which is representative of repair processes. We investigated how the physicochemical properties of released fragments from a n-CuPc containing automobile coating changed in biological (cell culture) media, and identified the hazard of the released $\mathrm{n}$-CuPc based on the use of an in vitro macrophage model (J774 A1) (Yen et al., 2009; Clift et al., 2008, 2010, 2011). Fragments containing n-CuPc from automobile coatings (Frag n-CuPc), generated through a sanding approach, were compared with reference fragments without n-CuPc (Frag Refer) and pristine n-CuPc. We also investigated ROS production by these particles and their uptake by cells. Assessment of the potential for release and toxicity is important for the continued use and future of $\mathrm{n}-\mathrm{CuPc}$ in the specific context of its application in the automobile industry.

\section{Materials and methods}

\subsection{Release of $n$-CuPc fragments from automobile coatings as the result of sanding}

Sanding (Fig. 1A) was performed to produce fragments from automobile coatings containing $3.5 \%(\mathrm{~g} / \mathrm{g}) \mathrm{n}$-CuPc and a reference coating with the same matrix composition (polymer), but without n-CuPc (Fig. 1C). Release experiments were performed inside an aerosol chamber $\left(0.15 \mathrm{~m}^{3}\right)$ equipped with a drill (Bosch, GBS 21-2 RCT Professional) (Fig. 1A, SI Fig. 1). The sanding paper, with a grit size of 400 and a diameter of $115 \mathrm{~mm}$ (Starcke GmbH \& Co.KG), was attached to the drill head. Sanding was performed using a contact force of $17 \mathrm{~N}$ with a speed of $900 \mathrm{rpm}$ over $10 \mathrm{~s}$. The plates with n-CuPc coating and reference plates were fixed (Fig. 1B). For each plate, three areas of different area sizes $\left(19,21\right.$, and $\left.30 \mathrm{~cm}^{2}\right)$ were sanded. The sanded areas were changed through rotating the holder by an angle of 90 degrees (Fig. 1B). The releases of $\mathrm{n}$-CuPc fragments were limited in the implemented sanding process.
An appropriate experimental quality control was included. Even though drilling can generate aerosols, its impact was found to be small given that only the drilling head was inside the chamber in our experimental design while the motor was outside. The air inlet was HEPA filtered. Before and after each sanding event, the chamber was flushed using a pump to reduce the background particle concentration. Sanding fragments collected from the chamber were examined using optical microscopy. We observed that the sanding was not homogeneous across the entire sanded area, which occasionally resulted in the generation of steel fragments. The steel fragments were removed by magnet separation, sonication, and ultracentrifugation (15000 RPM, $1 \mathrm{~h}$, Beckman Optima XL-80 k. A swing-out rotor SW60 Titan) (SI Fig. 2). The separated fragments were analyzed by SEM and light microscopy (SI Fig. $3 \& 4$ ).

The number of fragments released as an aerosol during sanding was recorded using a condensation particle counter (CPC, TSI $3775,>2.5 \mathrm{~nm}$ ) and an optical particle sizer (OPS, TSI 3330, $0.3-10 \mu \mathrm{m}$ ) for both coatings. For the calculation of a total fragment number released during one sanding event the fragment numbers determined by CPC and OPS during both sanding and chamber evacuation afterwards were comprised. An arithmetic mean of these twelve (sanded 4 plates, each 3 times) sanding events was calculated for each material. The size of released fragments was analyzed by OPS $(0.3-10 \mu \mathrm{m})$ and microscopy (powder from released fragments). In addition, the fragments were collected from the chamber bottom after sanding and analyzed by Scanning Electron Microscopy (SEM). The quantity analysis of sanding fragments was conducted by comparable analysis between the calculated weight of coatings and sanding fragment weight of coatings (SI 3 ).

\subsection{Characterization of pristine $n-C u P c$ and sanding fragments in media}

The physicochemical properties of both the pristine n-CuPc and sanding fragments released from the automobile coatings were characterized in Rosewell Park Memorial Institute (RPMI-1640) medium (Sigma-Aldrich, Germany). The nominal mass concentration was $100 \mathrm{mg} / \mathrm{l}$ in RPMI medium. The agglomeration/aggregation of pristine $\mathrm{n}$-CuPc and the sanding fragments in RPMI was identified using an Analytical Ultracentrifuge (AUC) after $24 \mathrm{~h}$ incubation $\left(37^{\circ} \mathrm{C}\right)$.

The potential released ionic copper in RPMI medium at $0 \mathrm{~h}$ and after $24 \mathrm{~h}$ incubation $\left(37^{\circ} \mathrm{C}\right.$ ) was separated through stepwise filtration: $5 \mu \mathrm{m}$ filter (Sartorius Minisart 17594), $0.45 \mu \mathrm{m}$ filter (Millipore Millex-HV), and $0.02 \mu \mathrm{m}$ filter (Whatman Anotop 25 Plus) and analyzed by Inductively Coupled Plasma Mass Spectrometry (ICP-MS, Agilent 7500a).

\subsection{Macrophages model for $n$-CuPc toxicity}

\subsubsection{Cell culture}

The mouse macrophage J774 A1 cells were maintained in a $75 \mathrm{~cm}^{2}$ flask with RPMI-1640 cell culture medium in a humidified atmosphere of $37{ }^{\circ} \mathrm{C}, 5 \% \mathrm{CO}_{2}$. The RPMI medium contained phenol red, L-glutamine (1G) $(5 \mathrm{ml}$ at $2 \mathrm{mM})$ (Sigma-Aldrich, UK), penicillin $(5 \mathrm{ml}$ at $\left.100 \mathrm{U} \mathrm{ml}^{-1}\right) /$ streptomycin (P/S) $\left(5 \mathrm{ml}\right.$ at $0.1 \mathrm{~g} \mathrm{ml}^{-1}$ ) (Sigma, UK) and $10 \%$ heat-inactivated Fetal Calf Serum (FCS) (Gibco ${ }^{\circledR}$, UK) (hereafter known as complete medium). J774 A1 cells were removed from the culture flask via gentle scraping and then re-suspended in complete medium prior to centrifugation at $2000 \mathrm{RPM}$ for $2 \mathrm{~min}$. Cell viability was determined using Trypan blue ( $0.4 \%$ solution diluted in phosphate buffered saline (PBS)) exclusion. Cells were adjusted to give a suspension of $5 \times 10^{5}$ cells $/ \mathrm{ml}$ in complete medium and used for all subsequent investigations.

\subsection{2. $n-\mathrm{CuPc}$ and fragment particles dispersion protocol}

The dry n-CuPc, Frag n-CuPc, and Frag Refer powders were wetted with dimethyl sulfoxide (DMSO, Sigma, D-8415) prior to sonication. A 


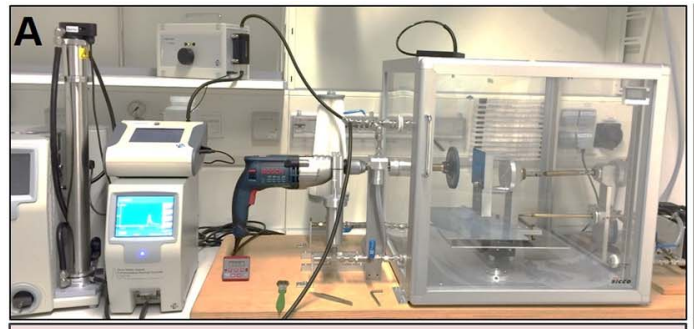

B

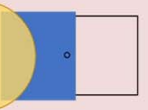

a

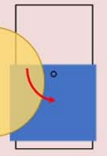

b

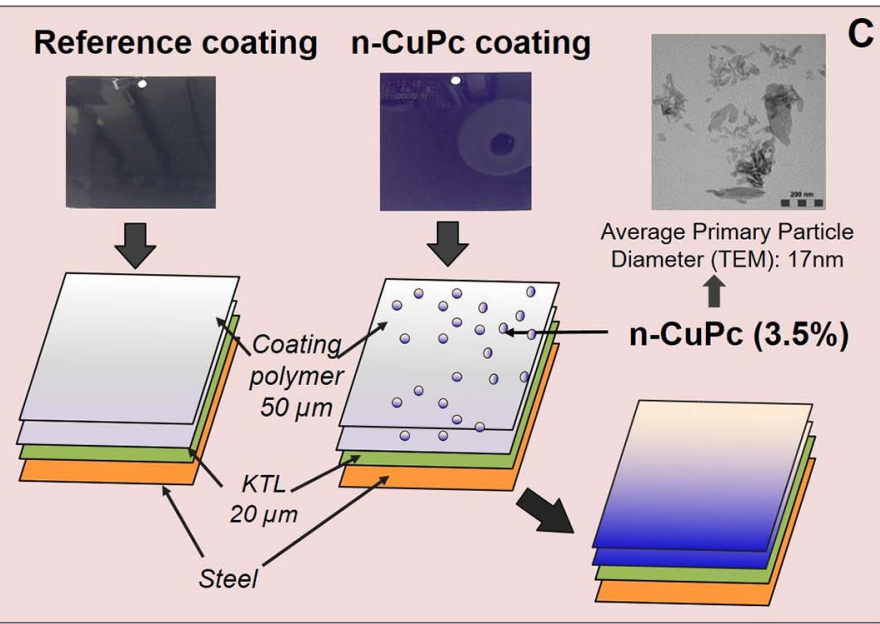

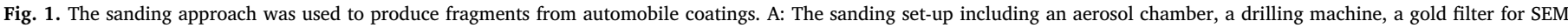

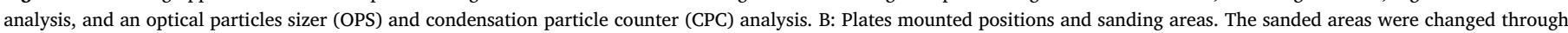

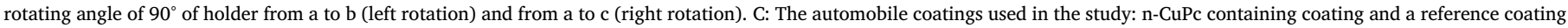
with same matrix composition, but without $\mathrm{n}-\mathrm{CuPc}$.

Table 1

Characterization of pristine $\mathrm{n}-\mathrm{CuPc}$ and fragment $\mathrm{n}$-CuPc in RPMI media.

\begin{tabular}{|c|c|c|c|c|c|}
\hline Media & Materials & $\begin{array}{l}\text { Size in } \\
\text { aerosol } \\
\text { (median } \\
\text { from OPS, } \\
\mu \mathrm{m} \text { ) }\end{array}$ & Test time & $\begin{array}{l}\text { Size in medium } \\
\text { (DLS: average, } \\
\text { AUC: median, nm) }\end{array}$ & 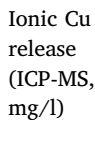 \\
\hline RPMI & $\begin{array}{l}\text { Pristine n- } \\
\text { CuPc } \\
\text { Fragment } \\
\text { n-CuPc }\end{array}$ & 1.57 & $\begin{array}{l}0 \mathrm{~h} \\
24 \mathrm{~h} \\
0 \mathrm{~h} \\
24 \mathrm{~h}\end{array}$ & $\begin{array}{l}\text { / } \\
333 \text { (AUC-UV) } \\
/ \\
\text { d50/nm: } 6141 \\
\text { (volume } \\
\text { distribution) } \\
\text { d50/nm: } 1015 \\
\text { (number } \\
\text { distribution) } \\
\text { (AUC-turbidity) }\end{array}$ & $\begin{array}{l}<0.05 \\
0.03 \\
<0.05 \\
0.08\end{array}$ \\
\hline
\end{tabular}

mass of $2 \mathrm{mg}$ of particles was weighed out each time and $40 \mu \mathrm{l}$ DMSO was added and the powder mixed by hand shaking $(1 \mathrm{~min})$. A volume of $2 \mathrm{ml}$ of complete medium was then added and sonicated for $16 \mathrm{~min}$ to make a stock solution. $\mathrm{CuSO}_{4}$ was added to deionized water to make the stock $\mathrm{Cu}^{2+}$ ion solution $\mathrm{A}$ and $\mathrm{B}$ (A: $137.5 \mathrm{mg} \mathrm{ml}^{-1}$; $\mathrm{B}$ : $1.925 \mathrm{mg} \mathrm{ml}^{-1}$ ). Cu ion A is equivalent to the copper in $\mathrm{n}-\mathrm{CuPc}(11 \%)$. It was used as a potential maximum release of copper ions. Solution B is equivalent to the copper ion concentration in Frag n-CuPc $(3.5 \% \mathrm{n}$ CuPc in automobile coatings, $11 \%$ copper in $\mathrm{n}-\mathrm{CuPc}$ ). $\mathrm{Cu}$ ion $\mathrm{B}$ is more representative of the actual measured release of copper ions in the exposure system used here (Table 1 ).

\subsubsection{WST-1 cell viability assay}

The J774 A1 cells were seeded in 96-well plates $\left(5 \times 10^{4}\right.$ cells per well in $100 \mu$ of the cell culture medium) and incubated for $24 \mathrm{~h}$ at $37{ }^{\circ} \mathrm{C}$ and $5 \% \mathrm{CO}_{2}$. The cells were then exposed to either n-CuPc, Frag $\mathrm{n}$-CuPc, Frag Refer, $\mathrm{CuSO}_{4}$ representing the ion concentration in n-CuPc $(\mathrm{Cu}$ ion $\mathrm{A})$, the $\mathrm{Cu}$ ion concentration in Frag $\mathrm{n}-\mathrm{CuPc}(\mathrm{Cu}$ ion $\mathrm{B})$, or controls for $24 \mathrm{~h}$. Stock solutions of n-CuPc, Frag n-CuPc, and Frag Refer were diluted to concentrations of $0,1,50,100,150,175,200$, $250 \mu \mathrm{g} \mathrm{ml}{ }^{-1}$ using complete medium. The stock solution of $\mathrm{Cu}$ ion A was diluted to concentrations of $0,0.012,5.5,11,16.5,19.25,22$, $27.5 \mu \mathrm{g} \mathrm{ml}^{-1}$. Stock solution of $\mathrm{Cu}$ ion $\mathrm{B}$ were diluted to expected exposure concentrations of $0,0.0004,0.19,0.39,0.58,0.67,0.77$, $0.96 \mu \mathrm{g} \mathrm{ml}^{-1}$. Cells were exposed to particles and $\mathrm{Cu}$ ions for a period of $24 \mathrm{~h}$. After the incubation period, the medium was discarded from the wells and $90 \mu \mathrm{l}$ of fresh culture medium added followed by $10 \mu \mathrm{l}$ WST-1 per well (Roche, Germany). Plates were then incubated for $1 \mathrm{~h}$ at $37{ }^{\circ} \mathrm{C}, 5 \% \mathrm{CO}_{2}$. The supernatant was transferred to a fresh plate and the absorbance measured by spectrophotometry at $490 \mathrm{~nm}$ using a microplate reader (MRX Revelation, U.S.A.). Each experiment was repeated three times.

\subsubsection{Reactive oxygen species}

Intracellular reactive oxygen species production was measured using the carboxy-2',7'-dichloro-dihydro-fluorescein diacetate (DCFHDA) assay (Roche, Germany). The J774 A1 cells were seeded in 96-well plates ( $5 \times 10^{4}$ cells per well in $100 \mu \mathrm{l}$ of the cell culture medium) and incubated for $24 \mathrm{~h}$ at $37{ }^{\circ} \mathrm{C}$ and $5 \% \mathrm{CO}_{2}$. The cells were rinsed once with Hanks' Balanced Salt solution (HBSS) (Sigma, UK) and exposed to nCuPc, Frag n-CuPc, Frag Refer, Cu ion A, Cu ion B, or controls for $24 \mathrm{~h}$. The exposure concentrations of n-CuPc, Frag n-CuPc, and Frag Refer were $0,50,100,200 \mu \mathrm{g} \mathrm{ml}^{-1}$. The concentrations of $\mathrm{Cu}$ ion A were 0 , $5.5,11,22 \mu \mathrm{g} \mathrm{ml}^{-1}$. The exposure concentration of $\mathrm{Cu}$ ion $\mathrm{B}$ were 0 , $0.49,0.39,0.77 \mu \mathrm{g} \mathrm{ml}^{-1}$. Carbon black nanoparticles (NPCB) $(14 \mathrm{~nm})$ (Printex ${ }^{\circledR} 90$, Evonik Industries AG, Essen, Germany), previously found to induce ROS (Jacobsen et al., 2008), were used as positive control, at concentrations of $16,32,64 \mu \mathrm{g} \mathrm{ml}^{-1}$. We previously used a DCFH method which involved pre-loading of cells with this dye prior to particle treatments. This method only allows a short-term particle response and relies upon rapid generation of ROS production. We found that no particles induced DCFH oxidation with this method, while the oxidant controls did induce DCFH oxidation (SI Fig. 5). We, therefore, investigated the effect of longer particle treatments on intracellular ROS generation, where it is essential that the DCFH is added post-treatment. After $24 \mathrm{~h}$ of particle exposures, supernatants were removed and cells were washed once with HBSS. A concentration of $10 \mu \mathrm{M}$ DCFHDA was added to each well of a 96-well plate and the fluorescence monitored in a spectrophotometer (Excitation $485 \mathrm{~nm}$, emission $530 \mathrm{~nm}$ ) (SpectraMax M5 Microplate Reader, Molecular Device, U.S.A.) every 15 min and stopped at $2 \mathrm{~h}$. Each experiment was repeated 3 times, and results were illustrated as the mean $+\mathrm{SD}$ change in fluorescence over time (fluorescence at $2 \mathrm{~h}$ minus fluorescence of $15 \mathrm{~min}$ ).

\subsubsection{Intracellular particles localization}

To study intracellular particle localization, J774 A1 were cultured in a 24-well plate with $10 \mathrm{~mm}$ glass sterile coverslips at a density of $5 \times 10^{5}$ cells $/ \mathrm{ml}$, and further exposed to $50 \mu \mathrm{g} \mathrm{ml}^{-1} \mathrm{n}$-CuPc, Frag n$\mathrm{CuPc}$, and Frag Refer for $24 \mathrm{~h}$ in an environment of $37{ }^{\circ} \mathrm{C}, 5 \% \mathrm{CO}_{2}$. The 
images of n-CuPc, Frag n-CuPc and Frag Refer in J774 A1 were captured using a digital camera (EOS 60D, Canon, UK) and light microscopy (Axiovert 40C, Zeiss, Germany). The cells were stained using DiffQuik (ThermoFisher Scientific, UK) and then mounted on microscope slides using DPX mounting medium (Sigma, UK). The images of n-CuPc, Frag n-CuPc and Frag Refer in J774 A1 cells were analyzed by Zen lite 2012 (AX 10, Scope A1, Zeiss, Germany).

\subsubsection{Statistical analyses}

A minimum of three replicates were performed for each method used. A one-way analysis of variance (one-way ANOVA) with Dunnetts's post-hoc analysis was used to compare the differences between control and treatments. A two-way analysis of variance (two-way ANOVA) with Tukey's post-hoc analysis was used to compare the significant differences between treatments' group (SPSS 16.0, U.S.A.). p-Values $<0.05$ were regarded as statistically significant. Data were displayed as mean $( \pm \mathrm{SD}$ ) and were analyzed using Origin 8 software (OriginLab Corporation, MA. U.S.A).

\section{Results and discussion}

\subsection{The role of matrix in release of $n$-CuPc from automobile coatings}

Release of n-CuPc from automobile coatings has the potential to be controlled by encapsulation in a matrix which is of key importance when considering the risks associated with the use of these consumer products. If the embedded n-CuPc particles are not released during the product lifecycle, then the exposure and risk can be considered as relatively low. In our study, we measured the release of n-CuPc-containing fragments from automobile coatings through a sanding approach, which is representative of repair processes, although many other factors (e.g. the matrix, aging, weathering, the type of release process) can also influence nanoparticle release.

Our study shows that fragments released from coatings upon sanding are strongly influenced by the matrix rather than by the presence of n-CuPc. For instance, SEM images of fragment particles showed no morphological differences between reference and nanoparticles containing coatings either in the aerosol or in the dust collected from the chamber bottom (Fig. 2). Both the OPS and CPC results showed no significant difference between the number of fragments released from reference and $\mathrm{n}$-CuPc coatings, although the median for the reference coatings was a bit lower $\left(2.24 \times 10^{6} \pm 3.78 \times 10^{5} / \mathrm{cm}^{3}\right.$ versus
$2.93 \times 10^{6} \pm 3.95 \times 10^{5} / \mathrm{cm}^{3}$ ) (Fig. $\left.3 \mathrm{~A}, \mathrm{~B}_{1}, \mathrm{~A}_{2} \& \mathrm{~B}_{2}\right)$. The size range was also similar (number-based median of $2.1 \mu \mathrm{m}$ and mode $2.2 \mu \mathrm{m}$ for the reference coating and $1.6 \mu \mathrm{m}$ and mode $1 \mu \mathrm{m}$ for the n-CuPc containing coating) (Fig. $3 \mathrm{~A}_{3} \& \mathrm{~B}_{3}$ ). Given the polydispersed and multimodal particle size distribution, these differences are difficult to interpret. The similar size and the shape showed the same modes for the two materials with and without the n-CuPC. This confirms earlier observations on paints, which are close analogues to coatings except for the higher filler content in paints. The difference of the contribution of each mode are well within the range of differences typically observed on paints (Koponen et al., 2011).

Our results are consistent with several other studies which investigated abrasion of materials with and without nanofiller additive. For example, Göhler et al. (2010) found no significant difference in iron oxide particles released from white pigmented architectural coatings (on fiber cement), an identical material containing zinc oxide nanoparticles, and a control coating with no nanoparticle filler during mechanical sanding (Göhler et al., 2010). Vorbau et al. (2009) studied abrasion of zinc oxide nanoparticles in polyurethane, UV-curable clear coat, and white-pigmented architectural surface coatings matrix and found that the different matrices exerted a far greater influence on the total mass loss during abrasion than the presence or absence of zinc oxide nanoparticles. Koponen et al. $(2009,2011)$ demonstrated that adding nanoparticles to the studied products only vaguely affected the geometric mean diameters of the particle modes in the sanding dust when compared to their reference products based on their study on the particle size distributions $(5.6 \mathrm{~nm}-19.8 \mu \mathrm{m})$ and the total number of dust particles generated during sanding of nanoparticles-doped paints, lacquers, and fillers as compared to their conventional counterparts. Gomez et al. (2014) also showed that there were no significant differences in the particle size distributions when comparing sanding dust from epoxy-based polymers with and without carbon nanotubes, and paints with different amounts of nano-sized titanium dioxide.

These studies indicate that the surface chemistry of sanding fragments is dominated by the chemical nature of the matrix, not by the embedded nanoparticles. Additionally, the abrasion process may also directly impact on the concentration and size of released particles. For instance, Wohlleben et al. (2011, 2013) showed that simulated long term wear using a Taber abraser resulted in fewer released particles from carbon nanotube (CNTs)-based composites than more aggressive sanding processes applied to identical materials. Furthermore, a combined mechanical and chemical stresses applied to simple and multi-
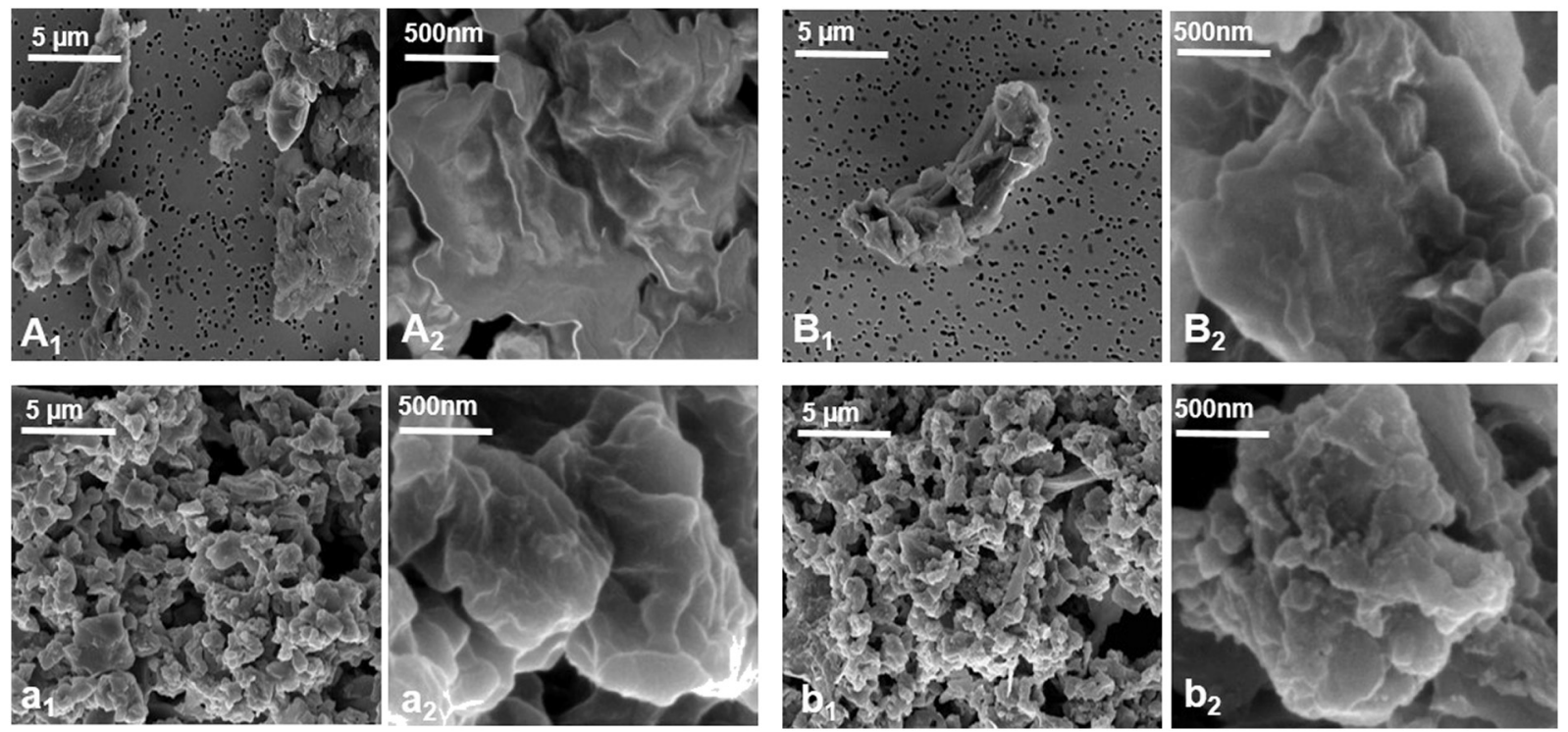

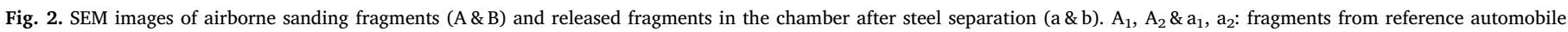
coatings; $B_{1}, B_{2} \& b_{1}, b_{2}$ : fragments from $n$-CuPc automobile coatings. 

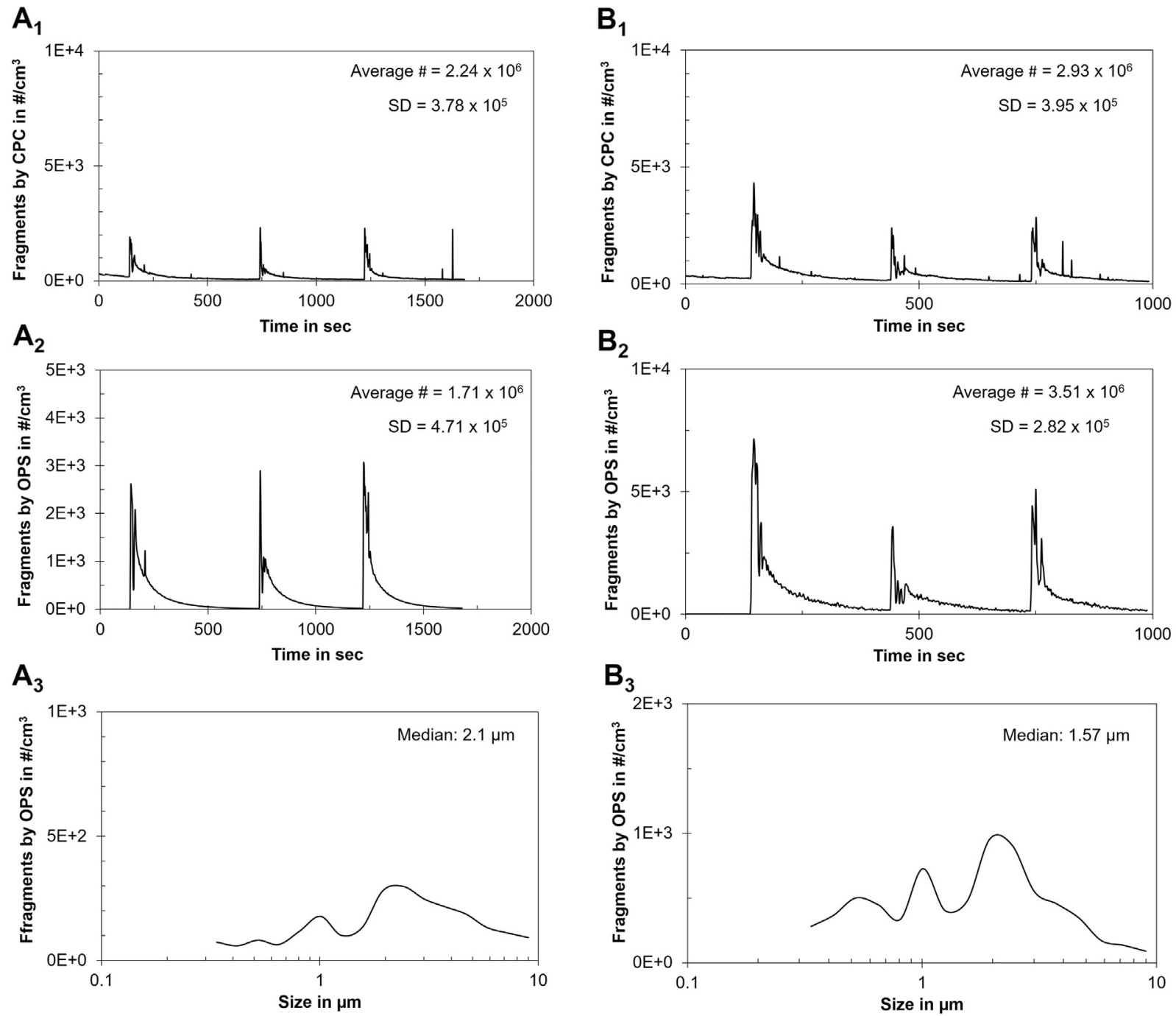

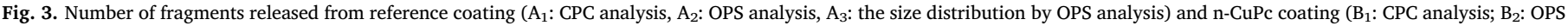
analysis; $B_{3}$ : the size distribution by OPS analysis). \#: the total number of fragments released from coating.

filler nanocomposites also can significantly impact the release of nanoparticles during in the real use phase of consumer products containing nanoparticles. For example, Wohlleben et al. (2016) found the importance of parameters controlling release phenomena overall decreases in the order: aging scenario-matrix properties-nanomaterial properties.

\subsection{Characterization of pristine $n-C u P c$ and sanding fragments in media}

Even though the reference and n-CuPc fragments were found to have similar physical properties (i.e., size distribution and other characteristics), it is important to study their behavior in hazard models relevant to potential exposure routes. Since Inhalation is the most relevant exposure route in the automobile (and repair) industry, macrophages representative of lung clearance and pro-inflammatory responses were investigated due to their phagocytic activity, resulting in a potentially relatively high exposure to this cell type. The physical chemical properties of sanding fragments as well as pristine $\mathrm{n}-\mathrm{CuPc}$ in macrophages cell culture were therefore examined.

After $24 \mathrm{~h}$ incubation of pristine $\mathrm{n}-\mathrm{CuPc}$ and sanding fragments in RPMI, the results of size distribution by AUC-UV and AUC-turbidity are shown in Table 1 and SI Fig. 6 (Wohlleben, 2012; Wohlleben et al., 2011, 2013; Walter et al., 2014). The size distribution analyses of pristine n-CuPc and Frag n-CuPc in RPMI showed that the dispersion of pristine $\mathrm{n}$-CuPc contained smaller particles than the Frag n-CuPc. However, this finding corresponds to agglomerates of a few to hundreds of pristine $\mathrm{n}$-CuPc fragment particles in RPMI, whereas the fragment particles were nearly individualized with a low level of agglomeration, because their size in medium corresponded well to their size directly after aerosol generation. For example, the AUC analysis showed that the size of frag $\mathrm{n}$-CuPc in RPMI media $(1.02 \mu \mathrm{m})$ is similar to their size directly after aerosol generation $(1.57 \mu \mathrm{m})$ if both are compared in the same metrics (number), using the well-established metrics conversion of AUC (Babick et al., 2016). Interestingly, the serum tends to reduce agglomeration of the pristine $\mathrm{n}-\mathrm{CuPc}$, but increase agglomeration of the fragments. The phenomenon may be due to the polymer exhibiting interaction with RPMI chemical components.

The analysis of ionic $\mathrm{Cu}$ release showed that both pristine $\mathrm{n}-\mathrm{CuPc}$ and fragment n-CuPc can release ionic $\mathrm{Cu}$ into RPMI media $(0.03 \mathrm{mg} / \mathrm{l}$ and $0.08 \mathrm{mg} / 1$ respectively) after $24 \mathrm{~h}$ incubation in $37^{\circ} \mathrm{C}$ (Table 1 ). However, the percent of released ionic $\mathrm{Cu}$ from both pristine n-CuPc and fragment $\mathrm{n}$-CuPc was very low $(0.27 \%$ and $0.21 \%$, respectively) which demonstrates that particles played role in the toxicity of n-CuPc fragment particles to macrophages. Even though the study showed a very limited release of ionic $\mathrm{Cu}$, several other mechanisms of n-CuPc automobile coating composite degradation, such as UV exposure, must be comprehensively evaluated under environmentally relevant conditions such as high light intensity, temperature cycles and humidity 
which may contribute to ionic $\mathrm{Cu}$ release from the coatings (Wohlleben et al., 2011, 2013).

\subsection{Toxicity associated with the released fragment $n-C u P c$ in macrophages} model

To assess the potential toxicity of released fragment n-CuPc from automobile coatings through the sanding process, cell viability, ROS production, and uptake images were examined after $24 \mathrm{~h}$ exposure of these particles to macrophages. The directly determined distribution of sedimentation coefficients in the specific cell culture medium give a speed of settling onto the cells. This approach, previously applied to all OECD sponsorship materials (Sauer et al., 2015) requires advanced analysis by AUC, but then replaces more involved models such as ISDD or the de Loid approach (Hinderliter et al., 2010; DeLoid et al., 2014). As the specific particles are all above $100 \mathrm{~nm}$, diffusion is a negligible factor against sedimentation. By integrating the distribution without any modeling we find that already after $1 \mathrm{~h}, 96 \%$ of the mass has settled onto the cells, and within $6 \mathrm{~h}$ also the smallest particles have settled onto the cells, so that the nominal dose is identical to the delivered dose at least from $6 \mathrm{~h}$ to $24 \mathrm{~h}$.

\subsubsection{Cell viability}

Cell viability testing results showed that a significant reduction in cell viability was only observed in the high exposure concentration $\left(150,175,200,250 \mu \mathrm{g} \mathrm{ml}^{-1}\right)$ of n-CuPc, Frag n-CuPc, and Frag Refer to J774 A1 (p < 0.05) (Fig. 4A). The toxicity of n-CuPc to J774 A1 was significantly greater than the toxicity of Frag n-CuPc to J774 A1 $(\mathrm{p}<0.05)$. The cell viability of cells treated with Frag Refer and nCuPc to J774 A1 showed a marginal significant difference ( $p=0.061$, Two-way ANOVA, Tukey test) (Fig. 4A). There was no significant difference in the toxicity induced by Frag n-CuPc and Frag Refer at $24 \mathrm{~h}$. The $\mathrm{EC}_{50}$ of n-CuPc, Frag n-CuPc, and Frag Refer were 151.1, 242.9, and $246.6 \mu \mathrm{g} \mathrm{ml}^{-1}$, respectively (Fig. 4C).

The high $\mathrm{EC}_{50}$ value produced by the Frag $\mathrm{n}$-CuPc suggests that when the n-CuPc was embedded in a polymer its toxicity was reduced. The lack of difference in toxicity between Frag n-CuPc and Frag Refer can be explained by the fact that the matrix dominated the toxicity of released fragments, preventing the toxicity of the embedded n-CuPc (Wohlleben and Neubauer, 2016).

Our results are consistent with other studies which investigated in vitro or in vivo toxicity of sanding dust from paint containing nanoparticles ( $\mathrm{NanoTiO}_{2}$ and nano silica) (Wohlleben et al., 2011; Saber et al., 2012a, b; Kaiser et al., 2013) or from CNTs containing polymer composites (Hirth et al., 2013; Wohlleben et al., 2013; Ging et al., 2014; Schlagenhauf et al., 2015; Saber et al., 2016; Civardi et al., 2016). For example, Ging et al. (2014) demonstrated that the survival of Drosophila was reduced at each dose tested with free amine functionalized CNTs, while there was no toxicity when these CNTs were embedded in epoxy. Wohlleben et al. (2013) showed that there were no cytotoxic effects of Thermoplastic polyurethane (TPU) with or without CNTs on lung tissue in vitro. Saber et al. (2012a, b), 2016) found that there were no additive effects of adding CNTs to epoxies or adding $\mathrm{NanoTiO}_{2}$ to paint for any of the pulmonary endpoints in mice (pulmonary
A

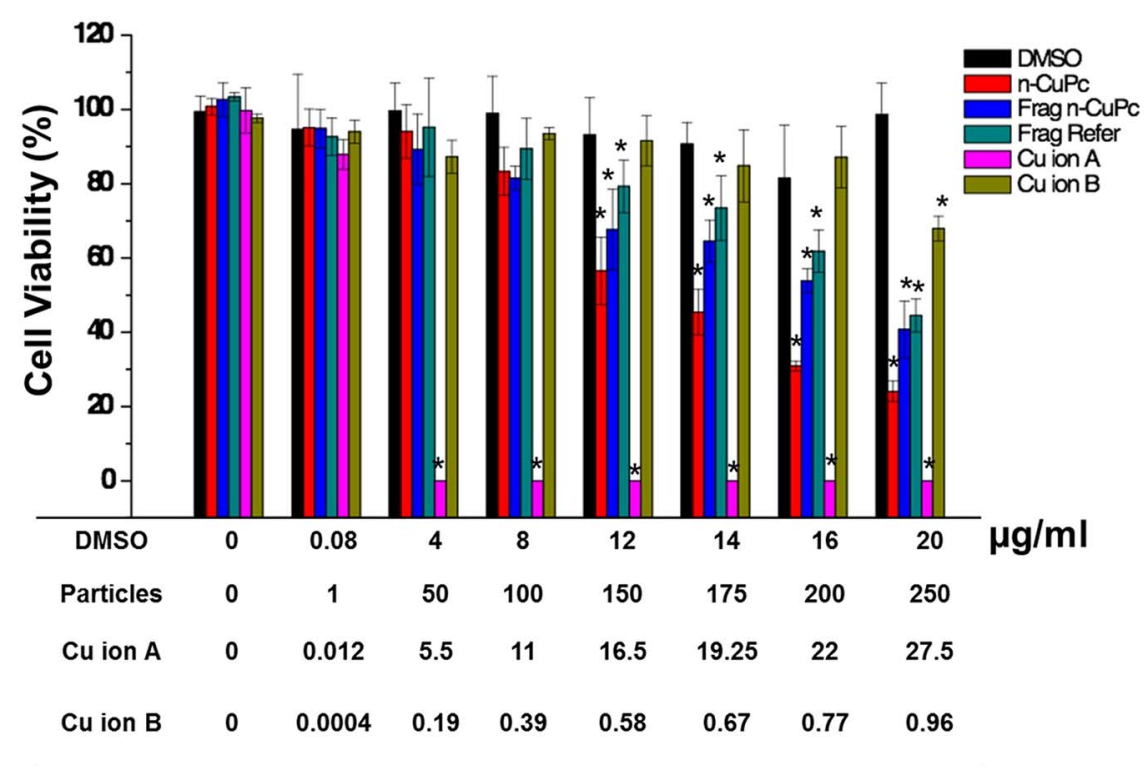

Fig. 4. (A) WST-1 assay of cell viability of n-CuPc, Frag n-CuPc, and Frag Refer to J774 A1 after $24 \mathrm{~h}$ exposure. The y axis represents the percent of cell viability compared to control. The $x$ axis represents the concentrations of particles or copper ion or DMSO. The value represents the mean \pm standard deviation of three replicates. (B) Cell viability of J774 A1 cells treated with nCuPc, Frag n-CuPc, and Frag Refer for $24 \mathrm{~h}$. (C) The EC50 values were determined using the software Origin 8. Data are shown as plots of the EC50 of n-CuPc, Frag n-CuPc, and Frag Refer to J774 $\mathrm{A} 1 \mathrm{for} 24 \mathrm{~h}$. The value represents the mean \pm standard deviation of three replicates.
B

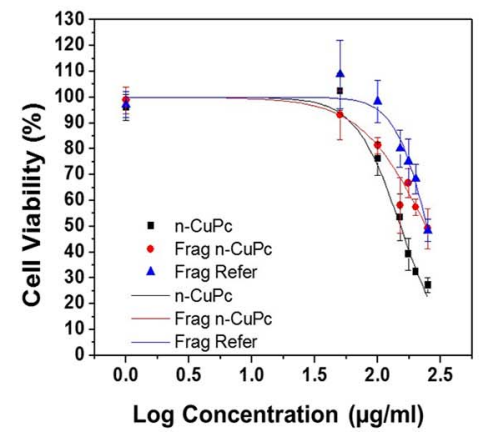

C

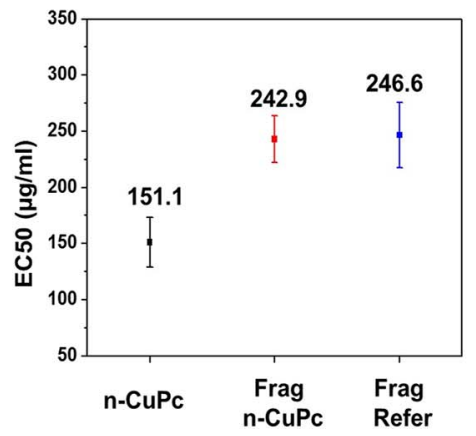


inflammation and DNA damage and hepatic histopathology). However, pure $\mathrm{NanoTiO}_{2}$ caused greater inflammation than $\mathrm{NanoTiO}_{2}$ embedded in the paint matrix.

Additionally, some released and toxicity study from other nanoparticles were also conducted. For instance, Kaiser et al. (2013) found that no differences in cytotoxicity were observed when CaCo-2 and Jurkat cells were exposed to free nanoparticles, the paint particles without nanoparticles, and the nanoparticle-containing paint particles. Civardi et al. (2016) also demonstrated that no additional release of nanoparticles from the abrasion of wood surfaces pressure-treated with micronized copper azole (MCA) wood and no specific nano-toxicity for lung epithelial cells and macrophages from these abrasion fragments. All of these studies indicated that nanoparticles embedded in a polymer had reduced toxicity and these materials were safe for use in industry and consumer products.

The $\mathrm{Cu}$ ion A induced a significantly toxic effect to J774 A1 cells $(p<0.05)$ at the concentration of $5.46 \mu \mathrm{g} \mathrm{ml}^{-1}$ treatment, which is equivalent to the $\mathrm{Cu}$ content in $\mathrm{n}-\mathrm{CuPc}$ at a dose of $50 \mu \mathrm{g} \mathrm{m} l^{-1}$ (Fig. 4A), at which dose the n-CuPC was not toxic. There is no significant toxicity of $\mathrm{Cu}$ ion B to J774 A1 (Fig. 4A), so that even if all $\mathrm{Cu}$ leached from Frag n-CuPc, it would not have had an effect. Our results indicate that when dose is expressed as $\mathrm{Cu}^{2+}$ instead of total mass, the toxicity of the Frag n-CuPc was very low compared to $\mathrm{Cu}^{2+}$ from $\mathrm{CuSO}_{4}$. This suggested the $\mathrm{Cu}^{2+}$ in the fragments was not bio-available and the toxicity of $\mathrm{Cu}$ was suppressed by the containment in particles.

\subsubsection{Reactive oxygen species (ROS)}

Reactive oxygen species constitute a major defense mechanism of the host cells against microbes such as intercellular parasites (FonsecaSilva et al., 2013), viruses (Imai et al., 2008) and other potential toxins, such as nanoparticles (Oberdorster et al., 2007; Brown et al., 2007; Kermanizadeh et al., 2012). The released $n-C u P c$ fragments may induce ROS production in the lungs if these particles were inhaled by workers in automobile industry. Therefore, we compared the capacity of n-CuPc, Frag n-CuPc and Frag Refer to induce ROS production in J774 A1 cells (Fig. 5). The results showed that $\mathrm{n}$-CuPc treatment of J774 A1 cells induced significant ROS production in a dose dependent manner at $24 \mathrm{~h}$ $(\mathrm{p}<0.05)$. However, Frag n-CuPc did not induce significant ROS production in J774 A1 cells exposed to the concentrations of 50, 100, and $200 \mu \mathrm{g} \mathrm{ml}^{-1}$ at $24 \mathrm{~h}$. A similar result was also shown for the Frag Refer (Fig. 5).

The results are consistent with other studies (Kaiser et al., 2013; Saber et al., 2012b). For instance, Kaiser et al. (2013) found that no release of ROS was observed when CaCo-2 and Jurkat cells were exposed to nanoparticles-containing paint particles $\left(243 \mu \mathrm{g} \mathrm{ml}^{-1}\right)$ and the same paint particles without nanoparticles $\left(243 \mu \mathrm{g} \mathrm{ml}{ }^{-1}\right)$ for $4 \mathrm{~h}$. Saber et al. (2012b) demonstrated that the sanding dusts from paints and lacquers with and without nanoparticles did not generate oxidative stress after $24 \mathrm{~h}$ intratracheal instillation of a single dose of $54 \mu \mathrm{g}$ in mice. Even though these ROS experiments were conducted in different target organisms and cells, the similar ROS production results indicated that nanoparticles embedded in a polymer can reduce ROS production.

$\mathrm{Cu}$ ion A showed significant ROS production in J774 A1 cells after $24 \mathrm{~h}$ exposure $(\mathrm{p}<0.05)$. The low concentrations of $\mathrm{Cu}$ in $\mathrm{Cu}$ ion $\mathrm{B}$ were insufficient to induce ROS production (Fig. 5). The results demonstrated that the high potential $\mathrm{Cu}$ ion release during other mechanisms of n-CuPc automobile coating composite degradation, such as UV exposure, high light intensity, temperature cycles and humidity may have effects on human health because of ROS production.

\subsubsection{Uptake images}

To further identify the uptake of Frag n-CuPc by J774 A1 cells, the interaction of the particles with J774 A1 was primarily studied by optical microscopy. The J774 A1 exposed to n-CuPc, Frag n-CuPc, and Frag Refer did not exhibit morphological changes compared to the control cells (Fig. 6). n-CuPc was observed more often in projection area of J774A1 cells than Frag n-CuPc and Frag Refer. Micrometre sized agglomerates of Frag n-CuPc and Frag Refer were observed to interact with J774 A1 cells as indicated by the dashed line arrow (Fig. $6 \mathrm{~A}_{3} \& \mathrm{~A}_{4}$ ).

The light micrographs and confocal micrographs of live J774 A1 cells exposed to n-CuPc for $24 \mathrm{~h}$ suggest that the n-CuPc could be taken up (SI Fig. $7 \mathrm{~A}_{2} \& \mathrm{~B}_{2}$ ). However, the images are not conclusive as they are two dimensional and the particles could be sitting on the cell surface. For this reason fixed $\mathrm{J} 774 \mathrm{~A} 1$ cells, which are unable to actively take up particles were exposed to the n-CuPc. For the fixed cells, subsequent exposure resulted in a homogeneous distribution of particles around the cells with no or few particles or agglomerates appearing on or in cells (SI Fig. $7 \mathrm{~A}_{3} \& \mathrm{~B}_{3}$ ). We performed this test to confirm that the conclusions made on the live-cell images were not just our subjective interpretation of uptake. By confirming that the appearance of fixed cells was different from live cells. The difference in appearance of fixed cells from live cells supports our hypothesis that the original images indicate uptake.

\section{Summary}

The high $\mathrm{EC}_{50}$ value and the relative lack of ROS production by the Frag $\mathrm{n}$-CuPc suggests that when the $\mathrm{n}$-CuPc is embedded in a polymer its toxicity is suppressed. The lack of difference in toxicity between Frag $\mathrm{n}-\mathrm{CuPc}$ and Frag Refer can be explained by the fact that the matrix

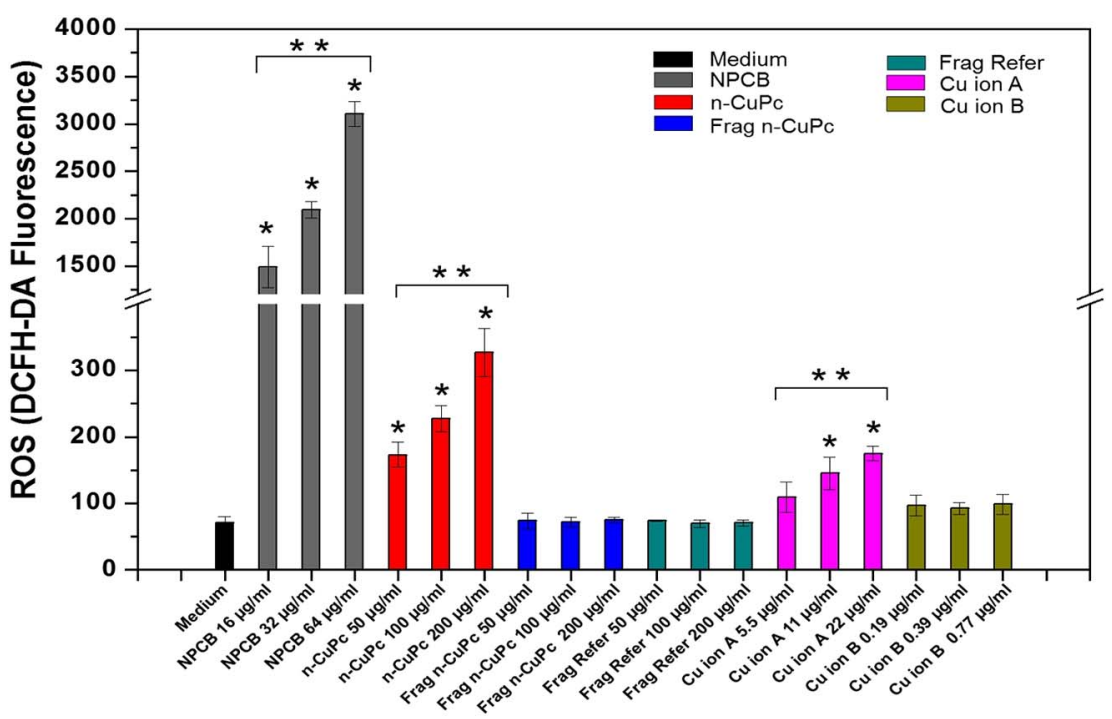

Fig. 5. ROS generation by n-CuPc, Frag n-CuPc, Frag Refer, NCBP, $\mathrm{Cu}$ ion $\mathrm{A}$, and $\mathrm{Cu}$ ion $\mathrm{B}$ in $\mathrm{J774} \mathrm{A} 1$ after $24 \mathrm{~h}$ exposure. ROS levels in J774 A1 cells were determined using H2DCF-DA. The asterisks * $\mathrm{p}<0.05$, comparing the untreated (medium) with treated (n-CuPc, Frag n-CuPc, Frag Refer, NCBP, Cu ion A, and $\mathrm{Cu}$ ion B) cells. ** $\mathrm{p}<0.05$, comparing the significant differences between treated cells. The value represents the mean \pm standard deviation of three replicates. 


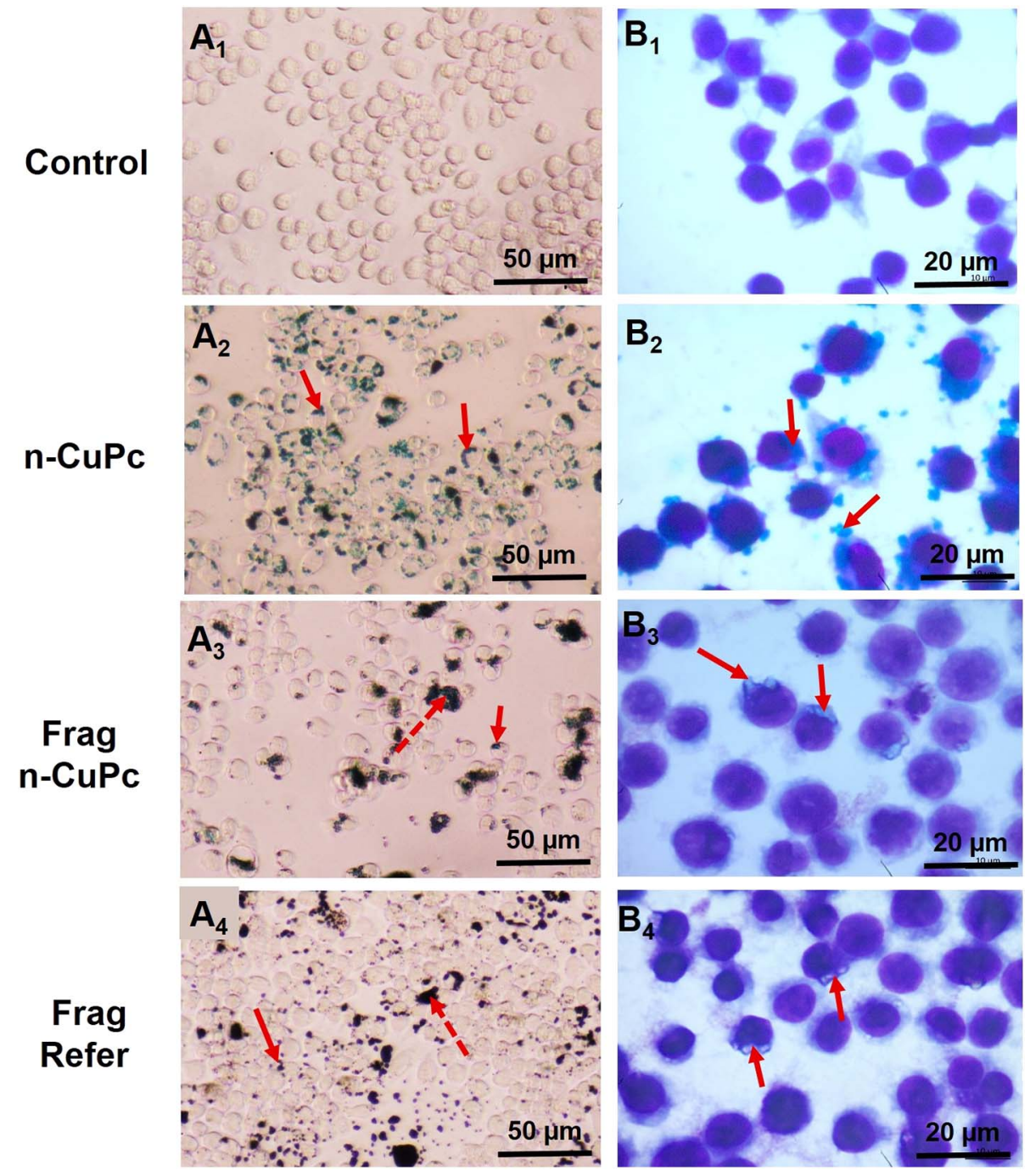

Fig. 6. Light micrographs of J774 A1 cells. Red arrows indicate the interaction between the particles and J774 A1 cells after exposure to $50 \mu \mathrm{g} \mathrm{m}^{-1} \mathrm{n}$-CuPc, Frag n-CuPc, and Frag Refer at $24 \mathrm{~h}$. (A) Cells were not stained. The dotted arrows in $\mathrm{A}_{3}$ and $\mathrm{A}_{4}$ showed aggregation of fragment particles $(40 \times)$. (B) Cells were stained with Diff-quik $(100 \times)$.

dominated the toxicity of released fragments, preventing the toxicity of the embedded n-CuPc. One hypothesis to explain the relatively low toxicity of the Frag n-CuPc could be that the bioavailability of n-CuPc is reduced. The micrometre agglomerates of Frag n-CuPc and Frag Refer (Fig. $6 \mathrm{~A}_{3} \& \mathrm{~A}_{4}$ ) may contribute to the lower uptake of fragments, resulting in a lower dose in the cells and therefore a low toxicity of fragments to J774 cells.

To the best of our knowledge, this is the first report concerning the cytotoxicity of released n-CuPc from automobile coatings to macrophages. Even though our findings are in general consistent with the finding of other studies on the toxicity of fragments from nano-enabled products, we are first to study the cross-linked, isocyanate-hardened matrix that is typical for coatings and is quite different chemistry than the soft polymer binders used in paints (Saber et al., 2012a, b), epoxy or thermoplastics (Saber et al. 2016; Wohlleben et al., 2011). We are the first to study copper-containing nanomaterial fillers, which a priori could result in quite different response than CNT fillers or TiO2 fillers in the (few) previous studies of fragment toxicity. Further, we combined assessment of both the release of nanoparticles in realistic conditions and the evaluation of hazard of the released fragments, specifically by using a macrophage model. In a preliminary risk screening, we evaluated the human risk to workers through the whole life cycle of the product. The study is thus very important to the automobile industry since it assesses the potential risk to the workers employed in this sector.

\section{Conflict of interest}

\section{Author declaration}

We wish to confirm that there are no known conflicts of interest associated with this publication and there has been no significant financial support for this work that could have influenced its outcome.

We confirm that the manuscript has been read and approved by all named authors and that there are no other persons who satisfied the criteria for authorship but are not listed. We further confirm that the order of authors listed in the manuscript has been approved by all of us.

We confirm that we have given due consideration to the protection of intellectual property associated with this work and that there are no impediments to publication, including the timing of publication, with respect to intellectual property. In so doing we confirm that we have followed the regulations of our institutions concerning intellectual property.

We understand that the Corresponding Author is the sole contact for the Editorial process (including Editorial Manager and direct communications with the office). He is responsible for communicating with the other authors about progress, submissions of revisions and final approval of proofs. We confirm that we have provided a current, correct email address which is accessible by the Corresponding Author and which has been configured to accept email from (marcom@unive.it). 


\section{Acknowledgements}

This research was funded by the European Commission Horizon 2020 Marie Sklodowska-Curie Individual Fellowships: NanoERA. Grant No.660960. The authors would like to thank Kai Werle and Klaus Vilsmeier from BASF for the characterization of fragments in relevant media.

\section{Appendix A. Supplementary data}

Supplementary data to this article can be found online at http://dx. doi.org/10.1016/j.impact.2017.06.002.

\section{References}

Babick, F., Mielke, J., Wohlleben, W., Weigel, S., Hodoroaba, V.-D., 2016. How reliably can a material be classified as a nanomaterial? Available particle-sizing techniques at work. J. Nanopart. Res. 18 (6), 1-40.

Bhattacharyya, A., Chattopadhyay, R., Mitra, S., Crowe, S.E., 2014. Oxidative stress: an essential factor in the pathogenesis of gastrointestinal mucosal diseases. Physiol. Rev. 94 (2), 329-354.

Brown, D.M., Hutchison, L., Donaldson, K., Stone, V., 2007. The effects of PM10 particles and oxidative stress on macrophages and lung epithelial cells: modulating effects of calcium-signaling antagonists. Am. J. Physiol. Ren. Physiol. 1;292 (6), L1444-L1451.

Chemical Economics Handbook, 2011. (Available at:). https://www.ihs.com/products/ chemical-economics-handbooks.html.

Civardi, C., Schlagenhauf, L., Kaiser, J., Hirsch, C., Mucchino, C., Wichser, A., Wick, P., Schwarze, W.M.R.F., 2016. Release of copper-amended particles from micronized copper-pressure-treated wood during mechanical abrasion. J. Nanobiotechnol. $14,77$.

Clift, M.J., Rothen-Rutishauser, B., Brown, D.M., Duffin, R., Donaldson, K., Proudfoot, L., Guy, K., Stone, V., 2008. The impact of different nanoparticle surface chemistry and size on uptake and toxicity in a murine macrophage cell line. Toxicol. Appl. Pharmacol. 1;232 (3), 418-427.

Clift, M.J., Bhattacharjee, S., Brown, D.M., Stone, V., 2010. The effects of serum on the toxicity of manufactured nanoparticles. Toxicol. Lett. 20;198 (3), 358-365.

Clift, M.J., Brandenberger, C., Rothen-Rutishauser, B., Brown, D.M., Stone, V., 2011. The uptake and intracellular fate of a series of different surface coated quantum dots in vitro. Toxicology 15;286 (1), 58-68.

DeLoid, G., Cohen, J.M., Darrah, T., Derk, R., Rojanasakul, L., Pyrgiotakis, G., Wohlleben, W., Demokritou, P., 2014. Estimating the effective density of engineered nanomaterials for in vitro dosimetry. Nat. Commun. 28, 5 .

Fonseca-Silva, F., Inacio, J.D.F., Canto-Cavalheiro, M.M., Almeida-Amaral, E.E., 2013. Reactive oxygen species production by quercetin causes the death of leishmania amazonensis intracellular amastigotes. J. Nat. Prod. 76 (8), 1505-1508.

Ging, J., Tejerina-Anton, R., Ramakrishnan, G., Nielsen, M., Murphy, K., Gorham, J.M., Nguyen, T., Orlov, A., 2014. Development of a conceptual framework for evaluation of nanomaterials release from nanocomposites: environmental and toxicological implications. Sci. Total Environ. 473, 9.

Göhler, D., Stintz, M., Hillemann, L., Vorbau, M., 2010. Characterization of nanoparticle release from surface coatings by the simulation of a sanding process. Ann. Occup. Hyg. 54, 615-624.

Göhler, D., Nogowski, A., Fiala, P., Stintz, M., 2013. Nanoparticle release from nanocomposites due to mechanical treatment at two stages of the life-cycle. In J. Phys. Conf. Ser. 429 (1), 012045 IOP Publishing.

Gomez, V., Levin, M., Saber, A.T., Irusta, S., Dal Maso, M., Santamaria, J., Jensen, K.A., Wallin, H., Koponen, I.K., 2014. Comparison of dust release from epoxy and paint nanocomposites and conventional products during sanding and sawing. Ann. Occup. Hyg. 16, meu046 (Jul).

Kittel, Hans, 1974. Lehrbuch der Lacke und Beschichtungen, Berlin. Wilfried Morley Morgans (ISBN: 9783879030439).

Hirth, S., Cena, L., Cox, G., Tomović, Ž., Peters, T., Wohlleben, W., 2013. Scenarios and methods that induce protruding or released CNTs after degradation of nanocomposite materials. J. Nanopart. Res. 15 (4), 1504. http://dx.doi.org/10.1007/s11051-0131504-x.

Hinderliter, P.M., Minard, K.R., Orr, G., Chrisler, W.B., Thrall, B.D., Pounds, J.G., Teeguarden, J.G., 2010. ISDD: a computational model of particle sedimentation, diffusion and target cell dosimetry for in vitro toxicity studies. Part. Fibre Toxicol. $30 ; 7$ (1), 36.

Imai, Y., Kuba, K., Neely, G.G., Yaghubian-Malhami, R., Perkmann, T., van Loo, G., et al.,
2008. Identification of oxidative stress and toll-like receptor 4 signaling as a key pathway of acute lung injury. Cell 133 (2), 235-249.

Jacobsen, N.R., Pojana, G., White, P., Moller, P., Cohn, C.A., Korsholm, K.S., Vogel, U., Marcomini, A., Loft, S., Wallin, H., 2008. Genotoxicity, cytotoxicity, and reactive oxygen species induced by single-walled carbon nanotubes and C(60) fullerenes in the FE1-Mutatrade markMouse lung epithelial cells. Environ. Mol. Mutagen. 49, 476-487.

Kaiser, J.P., Roesslein, M., Diener, L., Wick, P., 2013. Human health risk of ingested nanoparticles that are added as multifunctional agents to paints: an in vitro study. PLoS One 8 (12), e83215.

Kermanizadeh, A., Gaiser, B.K., Hutchison, G.R., Stone, V., 2012. An in vitro liver modelassessing oxidative stress and genotoxicity following exposure of hepatocytes to a panel of engineered nanomaterials. Part. Fibre Toxicol. 19;9 (1), 28.

Koponen, I.K., Jensen, K.A., Schneider, T., 2011. Comparison of dust released from sanding conventional and nanoparticle-doped wall and wood coatings. J. Expo. Sci. Environ. Epidemiol. 21, 408-418.

Koponen, I.K., Jensen, K.A., Schneider, T., 2009. Sanding dust from nanoparticle-containing paints: physical characterisation. J. Phys. Conf. Ser. 151, 012048.

Lin, M.T., Beal, M.F., 2006. Mitochondrial dysfunction and oxidative stress in neurodegenerative diseases. Nature 443 (7113), 787-795.

Lobo, V., Patil, A., Phatak, A., Chandra, N., 2010. Free radicals, antioxidants and functional foods: impact on human health. Pharmacogn. Rev. 4 (8), 118-126. http://dx. doi.org/10.4103/0973-7847.70902.

Oberdorster, G., Stone, V., Donaldson, K., 2007. Toxicology of nanoparticles: a historical perspective. Nanotoxicology 1 (1), 2-25.

Paiva, C.N., Bozza, M.T., 2014. Are reactive oxygen species always detrimental to pathogens? Antioxid. Redox Signal. 20 (6), 1000-1037.

Saber, A.T., Jacobsen, N.R., Mortensen, A., 2012a. Nanotitanium dioxide toxicity in mouse lung is reduced in sanding dust from paint. Part. Fibre Toxicol. 9, 4.

Saber, A.T., Jensen, K.A., Jacobsen, N.R., Birkedal, R., Mikkelsen, L., Møller, P., Loft, S., Wallin, H., Vogel, U., 2012b. Inflammatory and genotoxic effects of sanding dust generated from nanoparticle-containing paints and lacquers. Nanotoxicology 6, $776-788$.

Saber, A.T., Mortensen, A., Szarek, J., Koponen, I.K., Levin, M., Jacobsen, N.R., Pozzebon, M.E., Mucelli, S.P., Rickerby, D.G., Kling, K., Atluri, R., 2016. Epoxy composite dusts with and without carbon nanotubes cause similar pulmonary responses, but differences in liver histology in mice following pulmonary deposition. Particle and fibre toxicology 29;13 (1), 37.

Sauer, U.G., Aumann, A., Ma-Hock, L., Landsiedel, R., Wohlleben, W., 2015. Influence of dispersive agent on nanomaterial agglomeration and implications for biological effects in vivo or in vitro. Toxicol. in Vitro 28;29 (1), 182-186.

Schlagenhauf, L., Buerki-Thurnherr, T., Kuo, Y.-Y., Wichser, A., Nüesch, F., Wick, P., Wang, J., 2015. Carbon nanotubes released from an epoxy-based nanocomposite: quantification and particle toxicity. Environ. Sci. Technol. 49 (17), 10616-10623.

Vorbau, M., Hillemann, L., Stintz, M., 2009. Method for the characterization of the abrasion induced nanoparticle release into air from surface coatings. J. Aerosol Sci. 40, 209-217.

Walter, J., Löhr, K., Karabudak, E., Reis, W., Mikhael, J., Peukert, W., Wohlleben, W., Cölfen, H., 2014. Multidimensional analysis of nanoparticles with highly disperse properties using multiwavelength analytical ultracentrifugation. ACS Nano 8 (9), 8871-8886.

Wohlleben, W., Neubauer, N., 2016. Quantitative rates of release from weathered nanocomposites are determined across 5 orders of magnitude by the matrix, modulated by the embedded nanomaterial. NanoImpact 1, 39-45.

Wohlleben, W., Brill, S., Meier, M.W., Mertler, M., Cox, G., Hirth, S., von Vacano, B., Strauss, V., Treumann, S., Wiench, K., MaHock, L., Landsiedel, R., 2011. On the lifecycle of nanocomposites: comparing released fragments and their in-vivo hazards from three release mechanisms and four nanocomposites. Small 7, 2384-2395.

Wohlleben, W., Meier, M.W., Vogel, S., Landsiedel, R., Cox, G., Hirth, S., Tomovic, Z., 2013. Elastic CNT-polyurethane nanocomposite: synthesis, performance and assessment of fragments released during use. Nano 5 (1), 369-380.

Wohlleben, W., 2012. Validity range of centrifuges for the regulation of nanomaterials: from classification to as-tested coronas. J. Nanopart. Res. 14 (12), 1-18.

Wohlleben, W., Meyer, J., Muller, J., Müller, P., Vilsmeier, K., Stahlmecke, B., Kuhlbusch, T.A., 2016. Release from nanomaterials during their use phase: combined mechanical and chemical stresses applied to simple and multi-filler nanocomposites mimicking wear of nano-reinforced tires. Environ. Sci. Nano 3 (5), 1036-1051.

Yen, H.J., Hsu, S.H., Tsai, C.L., 2009. Cytotoxicity and immunological response of gold and silver nanoparticles of different sizes. Small 3;5 (13), 1553-1561.

Zhang, M., Yang, M., Bussy, C., Iijima, S., Kostarelos, K., Yudasaka, M., 2015. Biodegradation of carbon nanohorns in macrophage cells. Nano 7 (7), 2834-2840.

Zhao, F., Zhao, Y., Liu, Y., Chang, X.L., Chen, C.Y., Zhao, Y.L., 2011. Cellular uptake, intracellular trafficking, and cytotoxicity of nanomaterials. Small 7 (10), 1322-1337. 